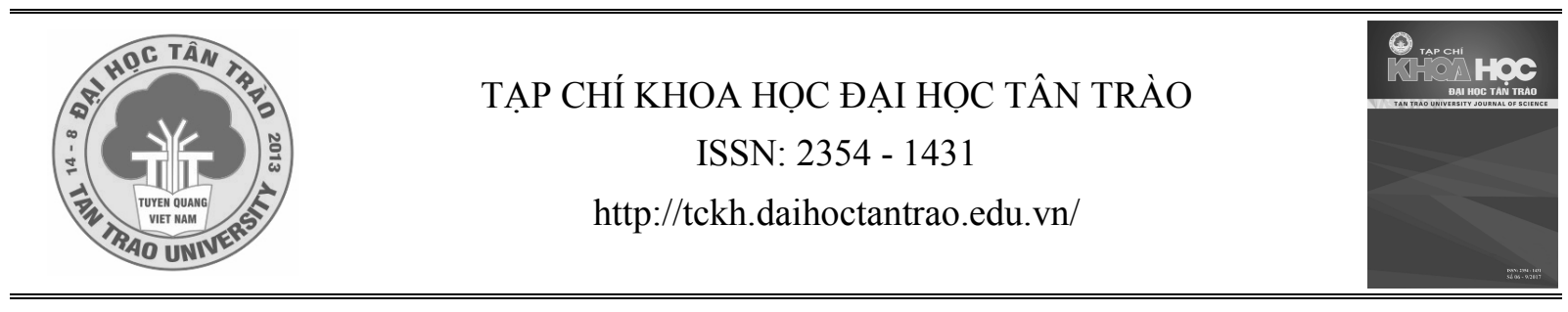

\title{
Bài tho "Ông đồ" của Vũ Đình Liên nhìn từ góc độ kí hiệu học văn bản
}

\author{
Lê Nguyên Cẩn ${ }^{a^{*}}$ \\ ${ }^{a}$ Trưòng Đại học Su pham Hà Nội \\ *Email:lenguyencan@yahoo.com.vn
}

\section{Thông tin bài viết}

Ngày nhận bài:

19/4/2017

Ngày duyệt đăng:

$10 / 3 / 2018$

\section{Tù khoá:}

Ki hiệu học; phân tích văn bản; phân tích kí hiệu học văn bản.

\begin{abstract}
Tóm tắt
Bài viết vận dụng cách thức phân tích văn bản văn học từ góc độ kí hiệu học văn bản để chỉ ra cái bi gắn với một thế hệ trong bước chuyển mình của lịch sử, được tái hiện trong bài thơ "Ông đồ" nổi tiếng của nhà thơ Vũ Đình Liên.
\end{abstract}

Trước hết, mỗi tác phẩm văn học, có thể dài có thể ngắn, có thể là một bài thơ vài ba câu, có thể là một tiểu thuyết nhiều tập.v.v. nhưng đều được coi là một văn bản được viết ra theo cách thức nghệ thuật, hàm chứa tính chất nghệ thuật, theo một khuôn thức hay một mô hình sáng tạo nghệ thuật đặc thù của ngôn ngữ, tuân thủ các đặc trưng của ngôn ngữ, được gắn kết theo các qui tắc ngữ pháp, được tổ chức theo trật tự cú pháp và đáp ứng cách thức sử dụng ngôn từ theo ngữ dụng học. Trong văn bản ấy, các từ ngữ, các cấu trúc ngữ pháp, các hình ảnh hình tượng, các lối nói, các cách thức diễn đạt qui ước...đều là những kí hiệu văn bản, gắn liền với văn bản và làm sáng tỏ thông điệp văn hóa mà văn bản muốn chuyển tới, đồng thời các kí hiệu này, ngoài nghĩa tự thân còn có nghĩa phái sinh hay chuyển đổi sang nghĩa khác mà đây chính là sức mạnh nghệ thuật của ngôn từ, tạo ra sự đa nghĩa, đa ngôn, đa dạng, đa hình, tạo ra 7/8 phần chìm của tảng băng như cách nói của E.Hemingway. Như vậy, kí hiệu học văn bản, một mặt là hình thức chuyển tải thông tin theo ý đồ của tác giả, mặt khác, là sự sáng tạo thông tin, qua các nghĩa mới - các nghĩa tạo sinh bằng chính sự kết hợp xảy ra giữa các kí hiệu, được tạo sinh bởi năng lực sáng tạo nghệ thuật của tác giả, thường vượt ra ngoài ý đồ chủ quan của tác giả. Nội dung thông tin đó ngoài nghĩa cụ thể thấy ngay còn có nghĩa hàm ẩn, chứa đựng các tầng nghĩa khác nhau trong văn bản văn học và phân tích văn bản văn học chính là làm sáng tỏ hay làm lộ ra các tầng nghĩa này và đọc văn bản tức là tìm hiểu nội dung các tầng nghĩa được sinh ra trong văn bản. Trong ý nghĩa này, ta dễ dàng thấy, thơ chính là cái nằm ngoài những gì được đọc qua sự tạo hình và qua âm thanh của các con chữ, nói rộng là nội dung của tác phẩm văn học nghệ thuật vượt ra ngoài khuôn khổ của tác phẩm văn học nghệ thuật đã đọc hay thưởng thức. Nghĩa của tác phẩm văn học là cái tạo ra sức sống bền vững cho tác phẩm văn học qua khả năng gợi mở liên tưởng, kích thích trí tưởng tượng và năng lực trí tuệ, kích thích khả năng ngôn ngữ của con người, theo cách từ gọi ra từ, kí ức gọi về kí ức. Cách hiểu này sẽ được vận dụng để phân tích bài thơ Ông đồ (1) của Vũ Đình Liên.

Cái nhìn bao quát toàn bộ bài thơ, cái nhìn tạo ra ý thơ và tứ thơ là cái nhìn hoài niệm. Xác lập điều này là rất quan trọng, bởi vì điểm nhìn nghệ thuật của chủ thể trữ tình trong thơ hay của người kể chuyện - người trần thuật trong văn xuôi, sẽ chọn ra các kí hiệu tạo thành văn bản và qui định cách thức sử dụng phù hợp các kí hiệu văn bản để tạo nghĩa. Cái nhìn hoài niệm ở đây được trải ra trên trục thời gian qua các từ ngữ hay kí hiệu chỉ thời gian hay ghi lại sự cảm nhận dấu ấn kỉ niệm của thời gian: Mỗi năm - lại thấy/ nhung - mỗi năm mỗi vắng - người viết thuê nay đâu/ năm nay không thấy. 
Bài thơ có năm khổ thơ, mỗi khổ bốn câu thơ, mỗi câu thơ năm chữ. Hình thức thơ năm chữ này cũng thực hiện chức năng tạo khắc ấn tượng, vừa là để tái hiện vừa để ghi lại, vừa minh định một ấn tượng, vừa mở ra một suy tư. Hình thức thơ năm chữ dứt khoát, lạnh lùng, rành rọt, mỗi chữ có sức nặng riêng của nó, có khả năng truyền cảm đặc biệt của nó, có trật tự không thể đảo ngược, diễn tả cái đã qua không trở lại, không thể níu giữ. Sự kiện của bài thơ chỉ là ấn tượng về ông đồ già bán chữ chúc phúc lúc năm hết tết đến mà sự kiện này được ghi lại bằng nét độc đáo ở Việt Nam: đó là hoa đào nở vào dịp tết đến xuân về, lúc cái nghèo được phô ra, cái giàu cũng có dịp thả sức khoe mình, nhưng giữa cái nghèo và cái giàu đều có chung niềm vui chia sẻ và khi không còn xảy ra sự chia sẻ đùm bọc thì tất yếu bi kịch nhân sinh xảy ra. Cái bi kịch đó cũng chính là bi kịch mang tính lịch sử của một thời mà tác giả - nhà thơ Vũ Đình Liên là một chứng nhân.

Khổ thơ đầu mang tới một thông báo, liên quan tới sự kiện tạo ra cảm xúc cho nhà thơ, liên quan tới ấn tượng tạo ra tứ thơ cho bài thơ: sự kiện về một ông đồ bán chữ treo tết. Câu "Mỗi năm hoa đào nơ" biểu thị tính thời gian rất độc đáo: vừa là thời gian bằng năm tháng lịch biểu (Mỗi năm) vừa là thời gian của cây cỏ chỉ thị mùa (hoa đào - nở). Từ " $m \hat{o ̂ i}$ " đi liền với từ "năm" cho thấy tính chất lặp lại, tính chất chu kỳ, nhưng bản thân từ " $m o \hat{o} i$ " còn tạo ra giá trị đồng qui, mang tính chất đồng qui, tạo điểm nhấn để sự "nô" của hoa đào xuất hiện. Từ "năm" là đơn vị đo thời gian, là một đại lượng thời gian mang tính chất chu kỳ, tuần hoàn. Nếu dùng chữ "hàng" (hàng năm) thì nghĩa của từ dù không thay đổi nhưng tình chất đồng qui không còn, vì từ "hàng" với thanh huyền của nó tạo ra sự dàn trải tán xạ mênh mông, chứ không mang tính qui tụ về một điểm.

"Hoa đào" là loại hoa đặc biệt, chỉ nở vào thời điểm đặc biết, thời điểm chuyển mùa cuối đông đầu xuân và cũng chỉ nở duy nhất một lần trong năm, cho thấy tính chất đặc thù của thời gian, ở đây, gắn với một sự kiện đặc biệt, một thời gian đặc biệt để tạo thành kiểu thời gian hoài niệm thời gian của kí ức. Việc chọn "hoa đào" cũng rất đặc biệt bởi lẽ hoa đào mang trong nó một giá trị văn hóa Việt: hoa của mùa xuân, hoa của xuân về tết đến, hoa của sự sang trang chuyển mình, nhưng là loài hoa hữu sắc vô hương.

Câu thứ hai mở đầu bằng từ "lại" có giá trị tạo khắc tính chu kỳ, tính lặp lại, để khẳng định một hành động, một sự quan sát, hay đúng hơn là một cái nhìn của nhiếp ảnh gia: "lại thấy”, nhấn mạnh tính ấn tượng của kỉ niệm đã được khắc vào trí nhớ và bức chân dung được tạo ra là một "ông đồ già". Chữ "lại” chỉ sự gặp gỡ của kí ức của kỉ niệm, của một sự kiện chỉ xảy ra một lần trong năm, không lặp lại trong cùng một năm, chỉ ra tính chất tạm thời, mỏng manh, tính không bền vững. Cụm từ "ông đồ già" mang trong nó khả năng giới thiệu hay tái hiện nhân vật từ nhiều góc độ: tuổi tác (già), giới tính (ông), nghề nghiệp (ông đồ) và theo đó là địa vị xã hội (địa vị của ông đồ trong xã hội) trong một hoàn cảnh mới được gợi ra bằng động từ mở đầu câu thứ ba: "bày". Khi liên tưởng "bày" (trong: bày hàng hóa, trưng các đồ vật ra, phô ra) với “ông đồ" ta sẽ thấy tính bi kịch của hoàn cảnh xuất hiện. Bởi vì hàng hóa mà ông đồ bày ra ở đây là mực tàu - giấy đỏ: những thứ thiêng liêng gắn với thời kì văn hóa chữ Hán, thời kỳ mà vị trí của ông đồ đang được coi trọng, trong một thế giới nếu chưa hẳn hoàn toàn xô bồ thì cũng đã khác nhiều: "bên phố đông nguời qua". "Mục tàu" và "giấy đò" gắn với hình thức cho chữ, xin chữ, thỉnh chữ rất thiêng liêng trong văn hóa thư pháp mà cái thiêng liêng đó là cái không thể mua bán. Người ta chỉ cho chữ, chỉ tặng chữ chứ không bán chữ, nhưng ở đây chữ đã trở thành yếu tố hàng hóa, và từ đó tính bi kịch của thời kỳ chuyển đổi lịch sử xuất hiện. Cho chữ, tặng chữ còn là thú chơ tao nhã của các bậc quân tử, là thể hiện tính chất tâm tình giữa những người có thiện lương và có tâm cảm thiện lương như trong Chữ người tử tù của Nguyễn Tuân.

Tính chất hàng hóa của mực tàu -giấy đỏ còn được thể hiện khá rõ ở câu mở đầu khổ thứ hai: "bao nhiêu nguời thuê viết", số lượng người đương nhiên không cụ thể nhưng cũng mang tính chất xác định bởi cấu trúc ngữ pháp của câu thơ: "bao nhiêu... thì... bấy nhiêu", tại sao công thức cấu trúc này là mang tính khẳng định, bởi vì cái "bao nhiêu” đó đều qui tụ lại ở sự đồng nhất ý kiến hay thống nhất về cách đánh giá: "tấm tắc ngợi khen tài" - một sự đánh giá được nhân lên tầng tầng lớp lớp: "tấm tắc" "ngơi $i$ " (trong ca ngợi) "khen" (trong khen ngợi), gắn với những yếu tố đảm bảo cho sự đánh giá cao và tập trung đó là "hoa tay" (khẳng định năng khiếu, tài năng đặc biệt), "thảo", "nhũng nét" - "nhu phuợng múa rồng bay" tức là đạt tới mức tinh túy, kết tinh thành cái đẹp cổ điển qua tính ước lệ của hình tượng rồng-phượng, nghĩa là các chữ viết trên tờ giấy đỏ 
bằng mực tàu ấy đều tạo ra những giá trị làm thỏa mãn thị hiếu của "bao nhiêu nguời", khiến họ thỏa mãn vì cái mà ông đồ già tạo ra đáp ứng thị hiếu công chúng tiêu dùng. Vì thế, tất cả đều "tấm tắc ngọi khen tài". Một từ cần được chú ý ở đây đó là "thảo". "Thảo" là một cách viết, là lối viết nhanh nhưng là cách viết đến mức điêu luyện, là tuyệt bút, và với lối viết "thảo" đã tạo ra sự tinh tế, tạo ra vẻ đẹp hấp dẫn đặc biệt, tạo ra linh hồn của con chữ, tạo ra cái "tài", cái "hoa tay" của người cầm bút, mà đây là một đặc điểm không thể thiếu được của nghệ thuật thư pháp: chỉ cần lướt bút mà tạo ra sức sống cho con chữ, tạo ra uy lực của chữ, tạo ra hồn của chữ, và những nhà thư pháp khi đạt được trình độ điêu luyện tinh tế như vậy thì được coi là người có thần bút. Ông đồ hiện ra ở đây cũng có thể coi là người đạt trình độ như vậy. Tất cả những lời đánh giá "tấm tắc ngọi khen tài" cũng như những nét "phuoơng múa rồng bay" đó không làm giảm bớt tính bi kịch của câu chuyện. Tính bi kịch này nằm ở cụm từ "thue viết". Ông đồ trở thành người bán chữ, không còn là người sáng tạo tinh thần mà trở thành người sản xuất vật chất. Ông đồ không còn là người dạy chữ thánh hiền hay cho chữ, tặng chữ thánh hiền nữa mà phải bán chữ dưới hình thức viết thuê, làm thuê để được trả tiền, cái tài viết chữ "phuợng múa rồng bay" trở thành phương thức kiếm sống của ông đồ già, cũng là của một thế hệ nho sĩ một thời, thời kỳ chuyển từ Nho học sang Tây học.

Tính bi kịch được gia tăng ở khổ ba, bằng từ "nhung" - cái từ tạo ra bước ngoặt hay sự đứt gãy vô phương cứu chữa bởi sự nhấn mạnh bằng hình thức so sánh tiếp đó: "Mỗi năm mỗi vắng" qua công thức so sánh tăng cấp "mỗi - mỗi". Sự so sánh đó còn được giải thích bằng một câu hỏi, nhấn mạnh tính chất bi kịch đã lộ ra ở khổ trên: "Người thuê viết nay đâu?". Tính chất làm thuê của ông đồ là không thể chối cãi, nhưng làm thuê cho ai thì cũng không rõ (người thuê viết nay đâu?), làm thuê nhưng vô chủ, ai cũng có thể thuê ông, nhưng chẳng ai chịu trách nhiệm về sự sống còn của ông, bởi lẽ cái ông có, cái "tài", "thảo" những nét "phuợng múa rồng bay" ấy không còn là thị hiếu của thời đại nữa, không còn là nhu cầu của thời đại nữa. Tới lúc đó ông đồ không còn ai thuê viết nữa, ông cũng không còn làm thuê cho ai được nữa, ông bị loại ra ngoài dòng chảy của cuộc sống. Cái chữ của ông đồ mất giá, sự học của chữ Nho mất giá, tới mức "Giấy đỏ buồn không thắm/Mưc đọng trong nghiên sầu...”. Giấy nhạt mực khô. Ở đây có cách chơi chữ khá đắt: đỏ và thắm; đỏ để cho thắm lại, càng đỏ thì càng thắm, đỏ và thắm phải quyện vào nhau thì mới tạo ra sinh khí cho con chữ, nhưng giờ đây "giấy đo" ấy được nhân hóa trong trạng thái tình cảm "buồn" dẫn tới màu đỏ phai đi, tờ giấy đỏ không còn thắm nữa, tính chất "buồn" của tờ "giấy đô" được cộng hưởng thêm bởi nỗi "sầu" của nghiên mực. Nếu "buồn" là trạng thái tình cảm bộc lộ ra bên ngoài, thì "sầu" là nỗi đau lặn vào bên trong, là nỗi buồn của nhận thức suy tư, của sự cảm nhận cái mất mát trong chiều sâu tâm khảm, là nỗi đau nhân tình thế thái. Cả "giấy" và "nghiên" đều được nhân hóa, đều mang nỗi buồn nhân sinh, nỗi buồn của thời thế sang trang, của nhân tình chuyển đổi, của cái tài xưa cũ, cái tài đã từng làm "vang bóng một thời", nay không còn chỗ đứng trong dòng chảy của cuộc đời.

Câu mở đầu của khổ thứ tư cho thấy sự hiện diện của ông đồ: "Ông đồ vẫn ngồi đấy" với cách nhấn mạnh bằng hình thức lặp lại "vẫn", theo công thức " $A$ vẫn là $A$ ", nổi tiếng với truyện ngụ ngôn "Mèo vẫn hoàn mèo" tràn đầy tính mỉa mai, miệt thị. Nhưng đây là sự hiện diện vô hồn, là sự hiện diện của cái thừa trong dòng chảy lịch sử, bởi nhân vật bị qui định bởi công thức " $A$ vẫn là $A$ ". Thừa, bởi không ai cần ông nữa, bởi ông cũng chẳng còn cần cho ai, ông chẳng biết nhập vào đâu, chẳng biết hướng về ai. Khi rơi vào trạng thái ấy, con người trở thành con người thừa, trở thành con người vô duyên và hết sức cô đơn. Điều này được khẳng định một cách phũ phàng: "qua đuờng không ai hay". Vẫn có người đi qua đấy, vẫn còn diễn ra cảnh "bên phố đông người qua" đấy, nhưng giờ thì chẳng ai quan tâm tới ông nữa. Tất cả chỉ còn lại là những khách qua đường, cái bi đát khiến ta nhớ lại "khách qua đường để hũng hờ chàng Tiêu". Ở đây, xuất hiện một cách chơi chữ khá đắt: "Lá vàng rơi trên giấy" cho thấy giấy bây giờ không còn màu nữa, cho dù qua từ "vàng" ta thấy có sự so sánh ngầm, cho thấy đâu đó màu của giấy vẫn là màu đỏ, nhưng "vàng" thì có mà "đô" thì không, cũng giống như lá cây màu xanh bây giờ đã hóa thành lá vàng rụng xuống, tạo thành dấu hiệu báo trước cái chết. Lá vàng rơi trong cảnh: "ngoài trời muxa bụi bay". Mưa bụi là hình thức của mưa xuân, nhưng mưa xuân đã cuối mùa, vì mưa xuân này chỉ để cho cây trút lá, cho những lá vàng rơi, cho sự thay đổi không thể đảo ngược của dòng chảy lịch sử, cho nỗi buồn 
càng trở nên bất tận, không ai sẻ chia với ông già trong khoảng trời trống vắng. "Ông đồ vẫn ngồi đó" trở thành pho tượng chết, pho tượng đánh dấu một mốc thời gian nghiệt ngã, đánh dấu sự chuyển đổi của nhân tình thế thái, của sự vô tình của lịch sử, cái lịch sử đã cuốn phăng theo nó những giá trị văn hóa của quá khứ.

Sự hoài niệm kéo chủ thể trữ tình trở về với thời khắc hiện tại, bằng một sự khẳng định: "Năm nay đào lại nơ". Cái hiện tại hiện ra sau sự hoài niệm. Chữ "lại" của khổ đầu tiên tái hiện ở khổ kết thúc bài thơ như là một cách nhấn nhịp, kèm theo đó là hình thức vận động theo chu kỳ vĩnh hằng của cây cỏ: “đào (lại) - nơ", như một so sánh. Ở đây xuất hiện hình thức nghệ thuật song đối quen thuộc của nghệ thuật thời xưa: cảnh cũ - người xưa. Cảnh cũ vẫn dường như nguyên vẹn, không thay đổi, hay chính xác hơn là vẫn vận động theo chu kỳ (đào nở - đào lại nở) còn người xưa thì không còn: "không thấy ông đồ xua". "Không thấy" đã cho thấy một sự đau xót, nhưng biến "ông đồ già" thành "ông đồxua" thì quả thật hết sức nghiệt ngã. Cái hiện tại, hay cái vừa mới đâu đó thôi đã bị đẩy vào một quá khứ tuyệt đối, người “ $x u a$ " đã trở thành người “cu " trong cái bát ngát mênh mông của thời gian, của chiều dài lịch sử dưới hình thức khẳng định: "muôn năm". Câu hỏi được đưa ra nhấn mạnh hơn tính chất không hề giảm bớt của sự nghiệt ngã: "Nhũng ngườ muôn năm cũ/Hồn ở đâu bây giờ?”. Sự hiện diện của ông đồ biến mất hay chìm hẳn vào chiều sâu của quá khứ qua sự tịnh tiến của thời gian, qua các tính từ chỉ sự biến đổi không cưỡng được của con người trong thời gian: già - xưa - cũ, một ông đồ già hóa thân vào trong lớp lớp "nhũng người muôn năm cü" - như một bề dày lịch sử nhưng là lịch sử của sự quên lãng, những người đã vĩnh viễn trở thành quá khứ (bởi gắn với “muôn năm”). Thân xác họ chẳng còn mà cái tinh túy của con người, cái phần "hồn" của những con người ấy cũng chẳng biết tồn tại hay vất vưởng lang thang phiêu dạt nơi chân trời góc bể nào. Dấu chấm hỏi hiện ra cuối bài thơ như nỗi u hoài trăn trở, như sự thảng thốt băn khoăn, như nỗi đau hoài niệm: "Hồn ở đâu bây giơ??".

Câu chuyện của ông đồ già là câu chuyện mang tính nhân sinh gắn với câu hỏi lịch sử cần giữ lại những gì của quá khứ, gạt bỏ hay bảo tồn, đa dạng hóa văn hóa hay giản lược văn hóa. Và đây chính là thông điệp mà Vũ Đình Liên, một trong bốn kỳ nhân đã chuyển dịch hết sức thành công và tài hoa "Nhũng ngườ khốn khổ" của Victor Hugo, gửi gắm lại trong thông điệp này, thông qua nỗi buồn về nhân tình thế thái của các chứng nhân - những người đã trải mình qua những biến động thăng trầm của lịch sử. Việc phân tích "Ông đồ" từ góc độ kí hiệu học văn bản minh chứng cho những điều đã nói ở trên.

\section{TÀI LIỆU THAM KHẢO}

1. Ngữ Văn 8, T2 - Sách giáo khoa, Nxb Giáo dục Hà Nội, 2008.

\section{The poem "The old scholar-teacher" of the poet Vu Dinh Lien - viewing from the perspective of semiotic literature}

\section{Le Nguyen Can}

\section{Article info}

Recieved:

19/4/2017

Accepted:

10/3/2018

Keywords:

Semiotics; textuel analysis; textuel analysis's semiotic.

\begin{abstract}
The article uses the analysis of literary texts from the perspective of semiotic literature to point out the bind of a generation in the historical transformation that is reproduced in the poem Ong Do of Vu Dinh Lien.
\end{abstract}

